
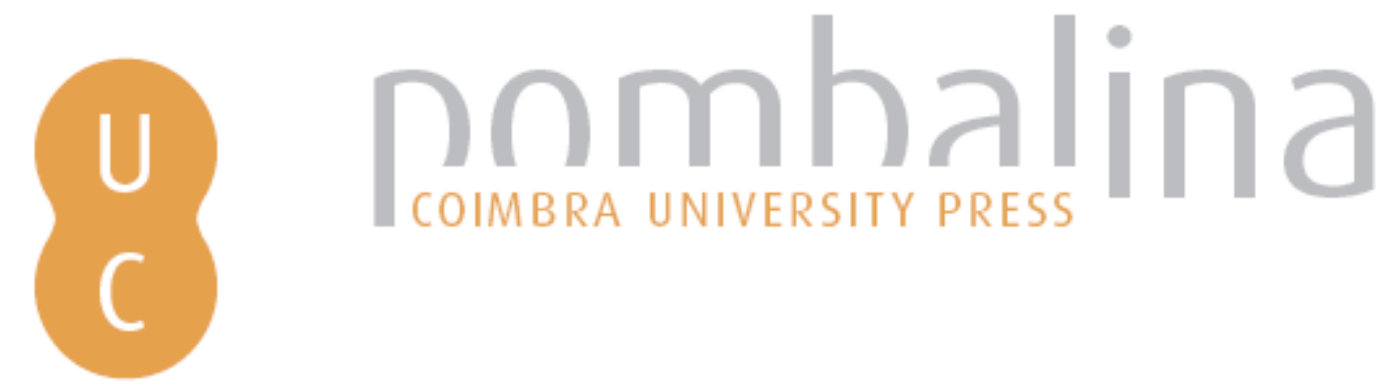

\title{
Uma proposta metodológica para o capítulo da geomorfologia de uma notícia explicativa de uma folha da Carta Geológica de Portugal (1:50 000)
}
Autor(es):
Marques, Eliane; Meireles, Carlos
Publicado por: Imprensa da Universidade de Coimbra
URL
persistente:
URI:http://hdl.handle.net/10316.2/37068
DOI:
DOI:http://dx.doi.org/10.14195/978-989-26-0983-6_15
Accessed : $\quad$ 26-Apr-2023 06:15:48

A navegação consulta e descarregamento dos títulos inseridos nas Bibliotecas Digitais UC Digitalis, UC Pombalina e UC Impactum, pressupõem a aceitação plena e sem reservas dos Termos e Condições de Uso destas Bibliotecas Digitais, disponíveis em https://digitalis.uc.pt/pt-pt/termos.

Conforme exposto nos referidos Termos e Condições de Uso, o descarregamento de títulos de acesso restrito requer uma licença válida de autorização devendo o utilizador aceder ao(s) documento(s) a partir de um endereço de IP da instituição detentora da supramencionada licença.

Ao utilizador é apenas permitido o descarregamento para uso pessoal, pelo que o emprego do(s) título(s) descarregado(s) para outro fim, designadamente comercial, carece de autorização do respetivo autor ou editor da obra.

Na medida em que todas as obras da UC Digitalis se encontram protegidas pelo Código do Direito de Autor e Direitos Conexos e demais legislação aplicável, toda a cópia, parcial ou total, deste documento, nos casos em que é legalmente admitida, deverá conter ou fazer-se acompanhar por este aviso. 


\section{$\forall$ \\ TAS DAS I JORNADAS LUSÓFONAS DE CIÊNCIAS E TECNOLOGIAS DE INFORMAÇÃO GEOGRÁFICA}

Editores

José Gomes dos Santos

Cidália Fonte

Rui Ferreira de Figueiredo

Alberto Cardoso

Gil Gonçalves

José Paulo Almeida

Sara Baptista 


\title{
ARTIGO 15
}

\section{UMA PROPOSTA METODOLÓgICA PARA O CAPítillo DA GEOMORFOLOGia de UMA NOtícia EXPlicativa de UMa Folha da Carta geológica de Portugal (1:50 000)}

\author{
MARQUES, Eliane ${ }^{1}$ \& MEIRELES, Carlos $^{2}$
}

Unidade de Geologia, Hidrogeologia e Geologia Costeira (UGHGC); Laboratório Nacional de Energia e Geologia (LNEG); Rua da Amieira - Apartado 1089; 4466-955 São Mamede de Infesta, Portugal; Tel: +351220 400 000; Fax: +351 229514 040; email: 1 eliane.marques@lneg.pt e 2 carlos.meireles@lneg.pt

\section{RESUMO}

Uma carta geológica é um documento cartográfico, de caráter científico e técnico, no qual, sobre um fundo topográfico apropriado transcreve-se, utilizando as técnicas e simbologia gráfica adequadas ao tema em questão, toda a informação respeitante aos materiais rochosos e aos fenómenos endógenos e exógenos que afetaram esses materiais (REBELO, 1999, 13). Geralmente, a edição de uma carta geológica faz-se acompanhar pela posterior publicação da respetiva Noticia Explicativa.

Uma Notícia Explicativa é um documento científico e técnico no qual é sintetizada toda a informação complementar, que pela sua natureza cartográfica, a carta geológica não permite comportar. Ambos os documentos refletem as consultas bibliográficas e a evolução dos conhecimentos científicos e técnicos à data da sua realização.

A Notícia Explicativa encontra-se subdividida em vários capítulos sendo um deles dedicado à geomorfologia da área em estudo, compreendendo uma descrição geomorfológica sintética. Contudo atendendo ao avanço científico nesta disciplina, é necessária uma caracterização geomorfológica, acompanhada de esboços e esquemas geomorfológicos mais detalhados. 
Assim sendo, este artigo enquadra-se no âmbito dos trabalhos que temos vindo a desenvolver, no sentido de estabelecer uma sistematização de parâmetros tendo em vista a reorganização do capítulo sobre a geomorfologia, bem como apresentar as bases metodológicas para uma futura Carta Geomorfológica de Portugal à escala 1:50 000 e respetiva Notícia Explicativa.

\title{
PALAVRAS-CHAVE
}

Carta geológica; Notícia explicativa; Geomorfologia; Esboço geomorfológico

\section{A METHODOLOGICAL PROPOSAL FOR THE} GEOMORPHOLOGY CHAPTER OF AN EXPLANATORY

NOTE OF A PORTUGUESE GEOLOGICAL MAP (1:50 000)

\begin{abstract}
Geological maps are highly scientific and technical documents, in which, information concerning rock materials and geological process are transcribed on a suitable topographic base (REBELO, 1999, 13). Generally, the issue of a geological map is accompanied by the publication of the respective Explanatory Note.

An Explanatory Note is a scientific document accompanying the publication of the geological map where more detailed and additional information is ascribed. As the geological map, the note reflects scientific and technical knowledge evolution at the date of its completion. Traditionally a geomorphological short description is part of this Explanatory Note. New parameters are proposed to reorganize the geomorphological item. This proposal will be the base for the future Geomorphological Map of Portugal, at 1:50 000 scale, and the respective Explanatory Note.
\end{abstract}

\section{KEYWORDS}

Geological map; Explanatory note; Geomorphology; Geomorphological sketch

\section{INTRODUÇÃo}

O conhecimento geológico, primordial para o desenvolvimento do país, é muitas das vezes veiculado através das cartas (designação geral para folha, mapa, esboço...) geológicas, sendo estas um meio singular de divulgação, no qual através de simbologia própria, transmite-se conhecimento adequado a todos quantos necessitam deste tipo de informação.

Uma Carta Geológica (Figura 1), é um documento científico e técnico onde se sintetiza, sobre um fundo topográfico adequado, informação rela- 
tiva aos materiais rochosos que ocorrem na região correspondente à área da carta, e aos fenómenos que os afetaram. Ou seja, é um instrumento que sintetiza o conhecimento geológico de determinada área. Consiste pois numa representação da intersecção dos contactos dos corpos geológicos com a superfície topográfica. Baseia-se em três tipos de informação: 1) dados concretos, objetivos, observados e medidos (ex. estruturas das rochas, relações espaciais entre corpos rochosos distintos); 2) interpretativos, determinado tipo de associação de rochas dão indicações sobre a sua génese. O grau de interpretação depende do nível de conhecimento e da experiência e perceção do geólogo; 3) relativos à idade, os eventos geológicos e as rochas têm de ser ordenados cronologicamente. Cada acontecimento geológico é único, cada afloramento, cada tipo de rocha tem propriedades intrínsecas, únicas, distintas de todos os outros.

Para além de toda a interpretação cronológica patente nos dados de caráter geológico, estrutural e tectónico, podemos ainda encontrar nas cartas geológicas informações relativas quer às sequências dos estratos, de acordo com os episódios de deposição ou erosão, à composição geoquímica das rochas e à consequente petrografia, quer a elementos relativos aos recursos minerais, hidrogeologia, paleontologia, arqueologia, e outros divulgados pela edição de cartas temáticas, elaboradas com objetivos específicos (CUNHA, 2008, 3-4).

Sendo estas referências fundamentais para quem trabalha na área da cartografia geológica, entendemos que é indissociável da realidade científica atual, obter qualquer tipo de mapa, sem uma adequada ligação do mesmo a uma bem estruturada base de dados de informação de caráter geológico que, por sua vez, atenda a todos os requisitos essenciais para um apropriado funcionamento do sistema de informação geográfica utilizado.

É comummente aceite que a geologia expressa na cartografia geológica, é um dos componentes indispensáveis de qualquer sistema integrado de gestão e planeamento do território. Todavia ainda podemos esperar novos desempenhos em termos de desenvolvimento eficaz na área dos sistemas de gestão de bases de dados geológicas. No entender de quem participa ativamente na elaboração de mapas geológicos, existe cada vez mais a necessidade premente de poder dispor de uma base de dados, 
compatível com as normas internacionais para a cartografia geológica, e ao mesmo tempo ser suficientemente interativa e dinâmica de modo a interligar vários temas, como a geomorfologia, por exemplo, de modo a facilitar, quer a elaboração da atividade cartográfica, quer uma mais adequada divulgação deste tipo de cartografia.

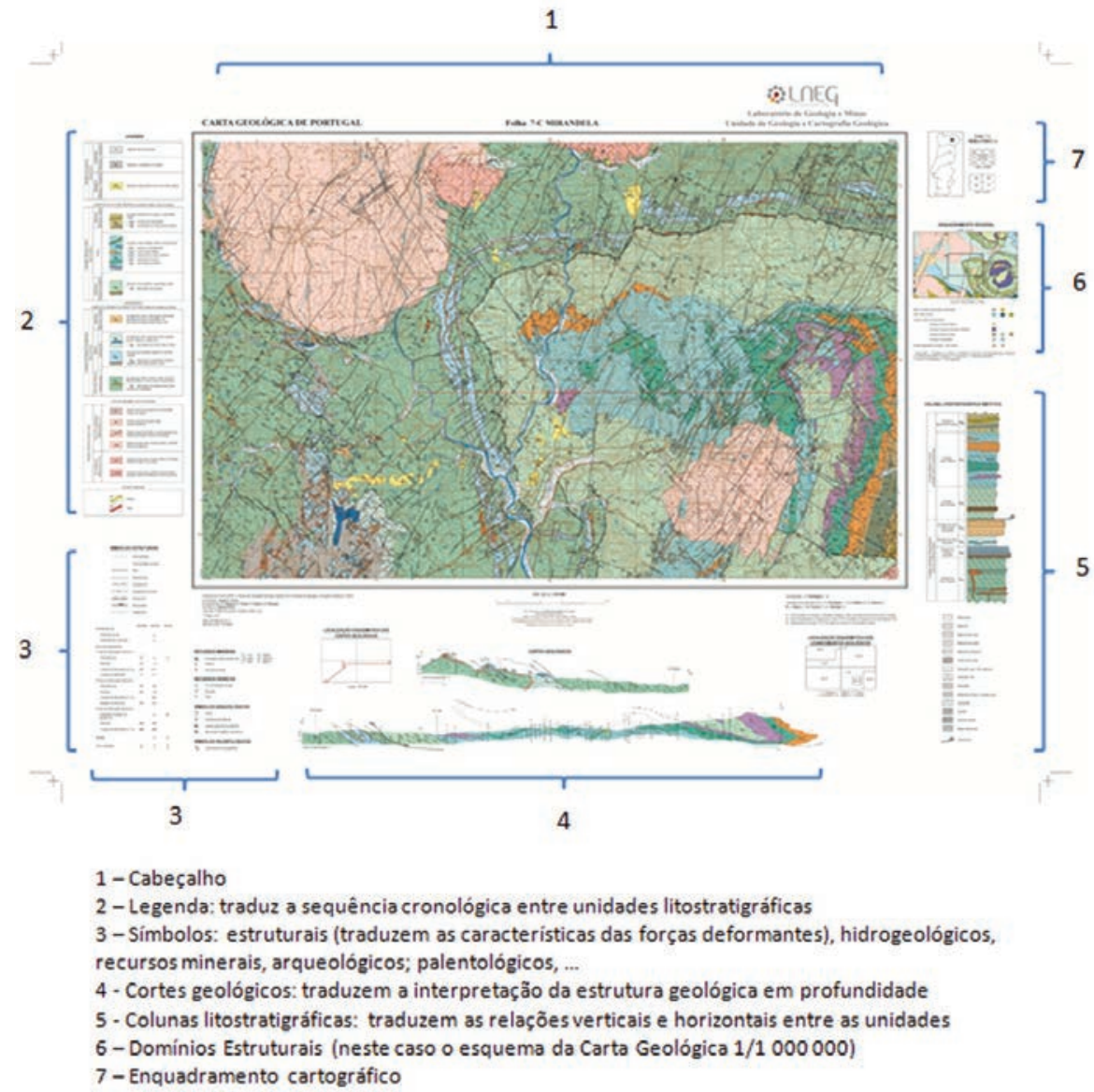

Figura 1 - Exemplo de uma carta geológica - Folha 7C - Mirandela, figura extraída de Marques (2012, apud RODRIGUES, 2010)

As folhas da Carta Geológica de Portugal (CGP) à escala 1:50 000, têm vindo a ser publicadas regular e sistematicamente desde os anos 50 do século passado, pela entidade nacional competente na matéria. ${ }^{1}$

11951 - Serviço de Fomento Mineiro - Direcção Geral de Minas e Serviços Geológicos (SFM-DGMSG, 1938-1959) - Início da publicação sistemática das folhas da CGP 1:50 000. Missão institucional continuada por outras instituições que entretanto foram sendo suces- 
É também parte integrante deste tipo de publicações a respetiva Notícia Explicativa, visando fornecer a todos os interessados informação complementar, que o mapa em si não permite comportar (Figura 2).

As Notícias Explicativas que acompanham as folhas das Cartas Geológicas são tradicionalmente organizadas em capítulos que, desde as primeiras edições até às mais atuais, como as Notícia Explicativa da Folha 17A-Viseu e da Folha 25C-Rosmaninhal (FERREIRA et al., 2010, ROMÃO et al., 2010), seguem, aproximadamente, a mesma organização: breve introdução, na qual os intervenientes na publicação são apresentados, segundo a sua área de conhecimento; referência a outros trabalhos publicados anteriormente sobre a área de trabalho em questão; descrição da geomorfologia; geologia (com subcapítulos relativos à estratigrafia, às rochas magmáticas intrusivas, às rochas filonianas); hidrogeologia; recursos geológicos (metálicos e não metálicos) e uma breve síntese sobre a arqueologia. Atualmente dá-se também maior destaque ao metamorfismo, à tectónica e à evolução geodinâmica da região em estudo bem como à componente do património geológico (locais de interesse geológico ou geossítios).

De acordo com a recolha de informação que fizemos, data de 1957 a primeira Notícia Explicativa com um capítulo dedicado à geomorfologia. ${ }^{2}$ Já na referida data o capítulo da geomorfologia descrevia os aspetos gerais do relevo da área, assim como os pontos notáveis (em termos altimétricos), e uma breve descrição da hidrografia.

Nesse sentido, não sendo inédita nas Notícias Explicativas, a presença de um capítulo sobre a geomorfologia da área de estudo, neste pequeno exercício é apresentada uma proposta de restruturação deste tema, passo fundamental para a apresentação das bases para uma futura Carta Geomorfológica de Portugal à escala 1:50 000 e da respetiva Notícia Explicativa, projeto este entretanto já antevisto em trabalhos anteriores

sivamente criadas e extintas: Serviços Geológicos de Portugal - Direcção Geral de Geologia e Minas (SGP-DGGM, 1939-1993); Instituto Geológico e Mineiro (IGM, 1993-2004); Instituto Nacional de Energia e Tecnologia (INETI I.P. 2004-2007); Laboratório Nacional de Energia e Geologia (LNEG I.P., 2007-?)

${ }^{2}$ COSTA, J. Carríngton and TEIXEIRA, Carlos (1957). Notícia Explicativa da Folha 9C - Porto. Lisboa, Serviços Geológicos de Portugal, 35 p . 
(MARQUES \& SOARES, 2011). Não está no âmbito deste pequeno resumo fazer um historial da Geomorfologia, como área científica que é, mas sim defender a aproximação entre a cartografia geomorfológica e geológica, nomeadamente na elaboração da Notícia Explicativa das folhas geológicas. A cartografia geomorfológica é muito específica, necessitando de uma base estrutural coerente sobre um fundo topográfico apropriado, como ponto de partida para a sua construção, sendo o LNEG o organismo público que pode fornecer a referida base estrutural. À semelhança do que acontece, por exemplo, no Instituto Geológico Y Minero de Espanha (IGME), a institucionalização da cartografia geomorfológica permitiria uma maior divulgação deste tipo de mapas.

A geomorfologia, e mais propriamente a cartografia geomorfológica, considerada como uma metodologia de investigação, é uma matéria que em nosso entender liga diretamente as área de conhecimento da geologia e da geografia. Contudo atendendo ao avanço científico nesta disciplina, é necessária uma caracterização geomorfológica mais detalhada, acompanhada de esboços e esquemas geomorfológicos apropriados, tendo em conta a necessidade de estabelecer uma nova sistematização de parâmetros de investigação.

Torna-se assim pertinente, fazer uma análise metodológica do que pode comportar, em nosso entender, o capítulo da geomorfologia a fim de estipular o que pode ser uma sequência de etapas de análise da área da folha em termos de descrição geomorfológica.

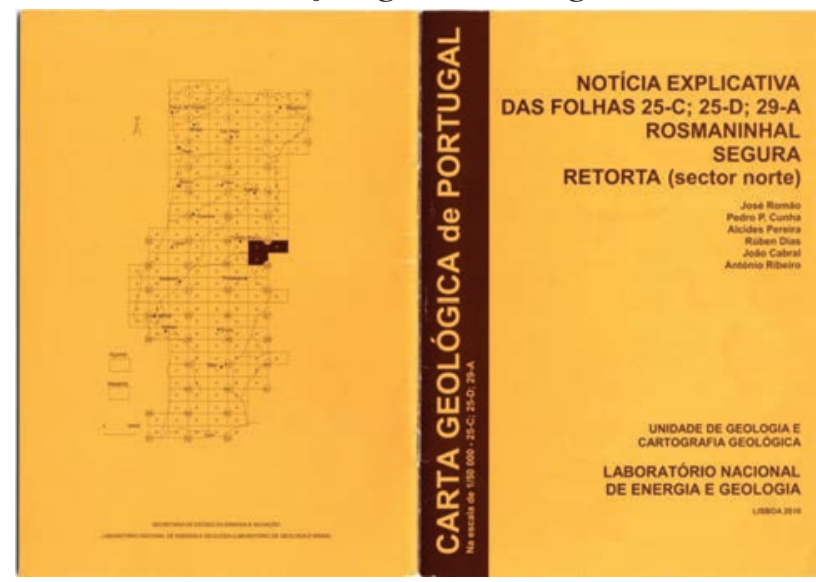

Figura 2 - Exemplo de Notícia Explicativa (frente e verso) 


\section{APRESENTAÇÃo DO TEMA}

A descrição dos aspetos ligados à geomorfologia da área de estudo, torna-se indispensável, visando não só uma correta caracterização dos processos que atuam na construção das paisagens, mas também concretizar um mais apropriado equacionamento das relações entre diferentes áreas do saber, que contribuem para uma adequada gestão e ordenamento territorial. No nosso entender, é assim indispensável a qualquer descrição ligada à estrutura geológica de uma Carta, descrever e compreender os aspetos ligados à construção das paisagens. O estudo dos agentes endógenos e exógenos, os processos pretéritos e atuais que estão na base da estruturação do relevo em análise, e sendo este o objeto de estudo da geomorfologia, parece-nos plenamente justificada a inclusão nas Notícias Explicativas, de um capítulo, mais alargado, dedicado aos aspetos geomorfológicos.

A leitura da geomorfologia de uma determinada área permite enfatizar as suas características litológicas, tectónicas, hidrológicas e climáticas (SILVA \& RODRIGUES, 2009, 86). Sob esse ponto de vista será antes de mais um reforço positivo, na aquisição de dados multidisciplinares para a compreensão das estruturas espaciais geradas por determinados fenómenos físicos. No mesmo sentido, é comummente aceite que sendo a cartografia geomorfológica uma metodologia de análise e meio privilegiado de transmissão de conhecimentos acerca do relevo, quanto à sua génese e evolução, a mesma seja parte integrante do capítulo da geomorfologia. É da conjugação destes pressupostos que parte a nossa base de raciocínio para a elaboração desta proposta metodológica.

\section{METODOLOGIA}

No seguimento da contextualização temática acima descrita, poderíamos estipular em 6 as etapas de caracterização relativamente aos aspetos geomorfológicos de uma determinada área, no caso específico, área correspondente a uma folha da Carta Geológica de Portugal à escala 1:50 000.

a) Introdução.

a.1) - Caracterização física da região: descrição fisiográfica - altimetria, 
hidrografia, pontos notáveis.

b) Unidades de relevo. Análise reacional dos agentes endógenos e exógenos atuantes na área em estudo.

b.1) - Descrições morfográficas e morfométrica: construção de mapas hipsométricos, de declives e orientações de vertente, delimitação de unidades de relevo dominantes (relevos estruturais, marginais, fluviais, litorais...). Agentes determinantes.

b.2) - Descrição morfogenética: agentes atuais e pretéritos que atuam como fatores desencadeantes do modelado da região.

b.3) - Descrição morfocronológica: aspetos relacionados com a paleogeografia.

c) Elementos estruturais.

c.1) Relacionamento das descrições anteriores com as unidades geológicas, estruturas e tectónica que encontramos na área de estudo.

d) Descrição morfoclimática.

e) Caracterização dos aspetos relacionados com a ocupação dos solos.

f) Caracterização dos aspetos económicos e sociais.

Todos estes parâmetros propostos encontram-se estruturados segundo uma lógica - aumento da complexidade da análise. Lógica essa que deverá estar sempre aberta à discussão com investigadores responsáveis pela cartografia geológica da área em questão. A inclusão dos dois últimos parâmetros, que em nosso entender seriam uma mais-valia para o projeto da folha em elaboração, permitiriam a aplicação do saber geográfico, que se distingue do geológico exatamente pela possibilidade de interligar os aspetos físicos e humanos de uma determinada região, o que, aliás, lhe confere identidade própria.

O desenrolar de todo este processo descritivo, deverá no nosso entender, e sempre que tal seja possível, ser acompanhado de esboços cartográficos que permitam uma identificação precisa da informação a ser construída. Ou seja, a elaboração de mapas de declives, mapas de orientação de vertentes, mapas de sombra, modelos digitais de terreno, perfis, etc., seriam etapas a implementar para a obtenção de normas de boas práticas em trabalhos deste género. Por outro lado, este grupo de mapas, poderiam ser parte integrante do sistema de gestão de dados geo- 
gráficos (SGDG) institucional, permitindo conjuntamente com a análise de dados de levantamento de campo e referências bibliográficas de base, estabelecer uma dinâmica interativa, que é o que se pretende aquando da implementação de todo e qualquer sistema de informação geográfica (ANDRÉ, 2004, 109).

\section{APRESENTAÇÃo dos dados}

Com base no que anteriormente foi descrito, foi preparada uma resenha do que será parte integrante da Notícia Explicativa da Folha 8A - São Martinho de Angueira (folha da CGP à escala 1:50 000 editada em dezembro de $2012^{3}$ ), estando para breve a sua publicação (Figura 3 ).

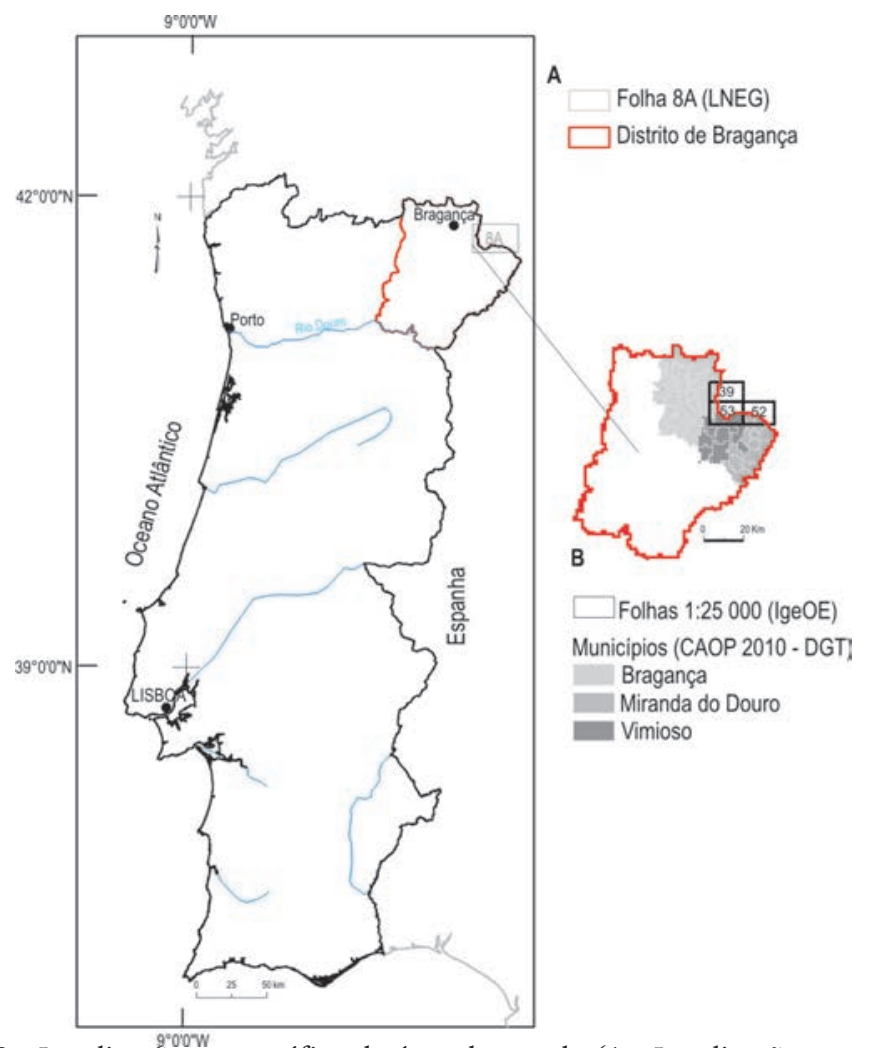

Figura 3 - Localização cartográfica da área de estudo (A - Localização no contexto da Península Ibérica; B - Localização no contexto regional, municípios do Distrito de Bragança que se localizam na área da folha $8 \mathrm{~A}$ )

${ }^{3}$ MEIRELES, Carlos (2012). Folha 8A - São Martinho de Angueira. Carta Geológica de Portugal à escala 1:50 000. LNEG. Lisboa, Laboratório Nacional de Energia e Geologia. 
Para a elaboração da nossa proposta foi necessário estabelecer um diagrama de fluxo de dados que integrasse os dados que seriam tratados, de modo a facilitar a organização da informação (Figura 4).

Um fluxograma, que neste caso traduz o fluxo de dados de um processo, é uma ferramenta que nos permite representar um processo de trabalho ou um algoritmo para a resolução de um determinado problema (ISO5807, 1985). Esta ferramenta representa o estado inicial de um problema e todas as atividades e decisões necessárias para sequencialmente se conseguir atingir um resultado final (GANE and SARSON, 1979, SOMMERVILLE, 2011). Neste caso, especificamente, trata-se de uma estruturação processual. Temos uma série de entidades de entrada (inputs) que alimentam o nosso sistema, como as fotografias, as imagens de satélite, os levantamentos de campo, entre outros. A conjugação destes dados gera a informação que pretendemos obter (outputs). Este modelo é um modelo simples e independente da tecnologia que eventualmente possa ser incorporada para a sua implementação.

A partir desta fundamentação acerca das relações entre os diferentes dados, realizou-se trabalho de campo específico para a análise geomorfológica da área de estudo, e reuniram-se os elementos necessários a todo o trabalho de gabinete que se seguiu. Partindo da fundamental base geológica, atualizada, fez-se a integração em base de dados de toda a informação topográfica e bibliográfica existente para a referida área.

Da estrutura anteriormente apresentada para a organização do capítulo foram sendo feitas adaptações, de acordo com o que é pretendido de forma a respeitar o objetivo de uma Notícia Explicativa. A arquitetura proposta para o referido capítulo está neste momento subdividida em:

a) Morfografia (formas dominantes) - descrição fisiográfica da área de estudo;

b) Morfogénese, morfocronologia e morfodinâmica da área de estudo;

c) Morfoclimatologia e características climáticas atuais;

d) Paisagem Humana (aspetos económicos e sociais); 


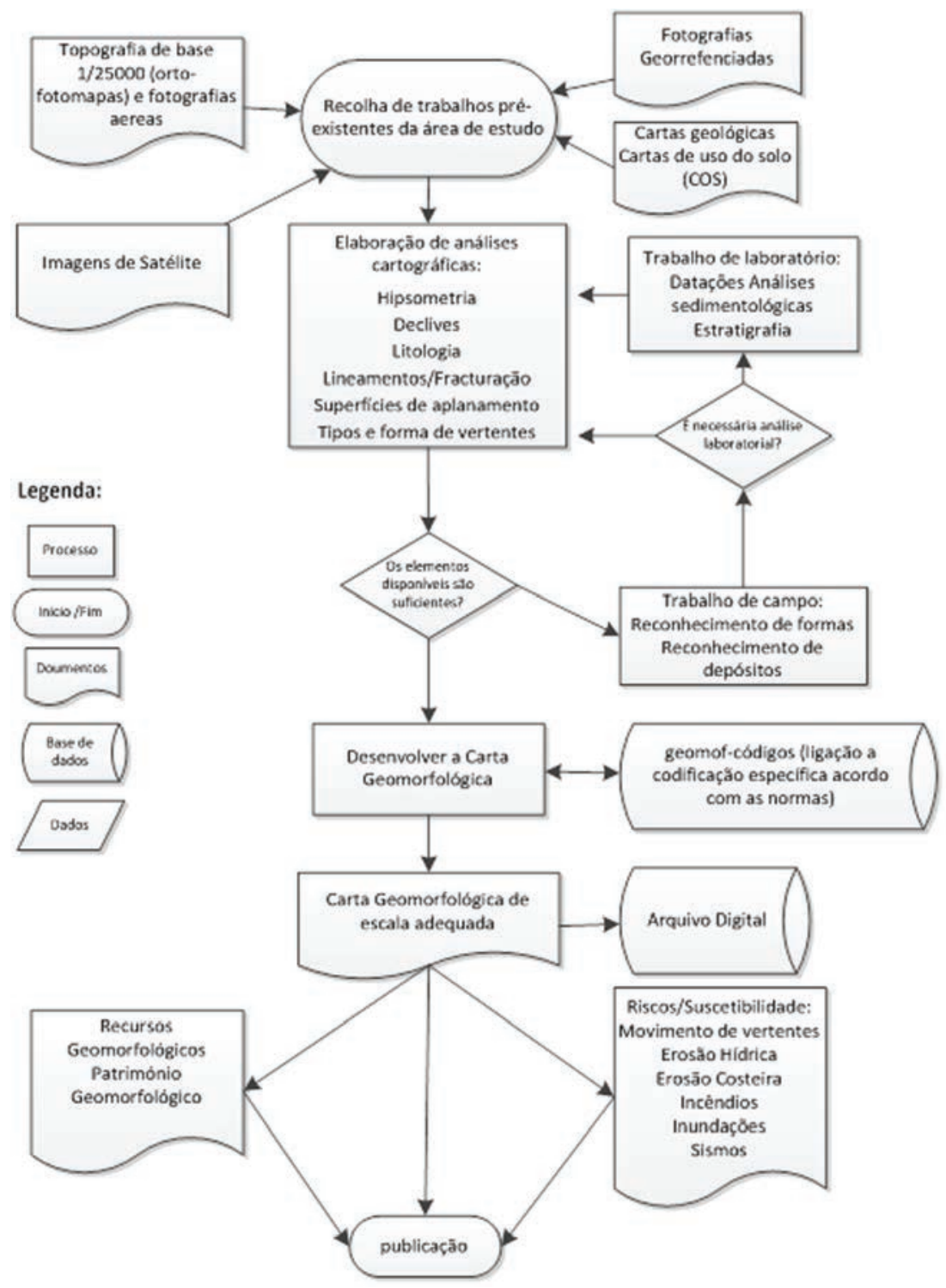

Figura 4 - Diagrama de fluxo de dados para elaboração de uma Carta Geomorfológica

Os aspetos relacionados com a morfografia (descrição geométrica das formas de relevo), morfometria (medidas quantitativas do relevo), morfocronologia (sucessão temporal das formas) e morfogénese (agentes e processos atuantes no modelado), assim como a morfodinâmica (agentes atuais e pretéritos), garantem ao esboço geomorfológico que acompa- 
nha o capítulo da geomorfologia uma leitura global indispensável para a articulação com os elementos topográficos, hidrográficos, tectónicos e litológicos que estão na base da cartografia geológica (MONNÉ, 1997, 15).

No seguimento desta breve resenha, visto o objetivo não ser uma descrição exaustiva dos aspetos geomorfológicos da área, mas sim uma contextualização da mesma, elaboramos um pequeno esboço cartográfico, à escala 1:50 000, que integra os aspetos geomorfológicos mais marcantes da área de estudo (Figura 5). Para a elaboração do referido esboço baseamo-nos em autores como Denise Brum Ferreira (FERREIRA, 1981), autora da única Carta Geomorfológica de Portugal, Laura Soares (SOARES, 2008), José Gomes dos Santos (SANTOS, 2005) e Carlos Bateira (BATEIRA, 2001). A semiologia gráfica empregue no referido esboço, será algo ainda em construção, mas baseia-se nos trabalhos publicados por estes autores, nos últimos anos. Nesse sentido, não sendo inédita a presença nas Notícias explicativas de um capítulo sobre a geomorfologia da área de estudo, neste pequeno exercício é apresentada uma proposta de restruturação deste tema, passo fundamental para a apresentação das bases para uma futura Carta Geomorfológica de Portugal à escala 1: 50 000 e da respetiva Notícia Explicativa, projeto este já antevisto em trabalho anterior (MARQUES \& SOARES, 2010).

\section{DisCUSSÃo DOS RESULTADOS}

O esboço geomorfológico apresentado, e o texto de enquadramento do mesmo, visa antes de mais o início de uma colaboração que se pretende vir a aprofundar. A construção de uma base de dados cartográfica, ligando a simbologia adequada à elaboração de mapas geomorfológicos, integrada na instituição que edita cartas geológicas, base fundamental de análise para a geomorfologia, parece-nos ser uma mais-valia que poderia ser tida em conta na elaboração de projetos futuros. 


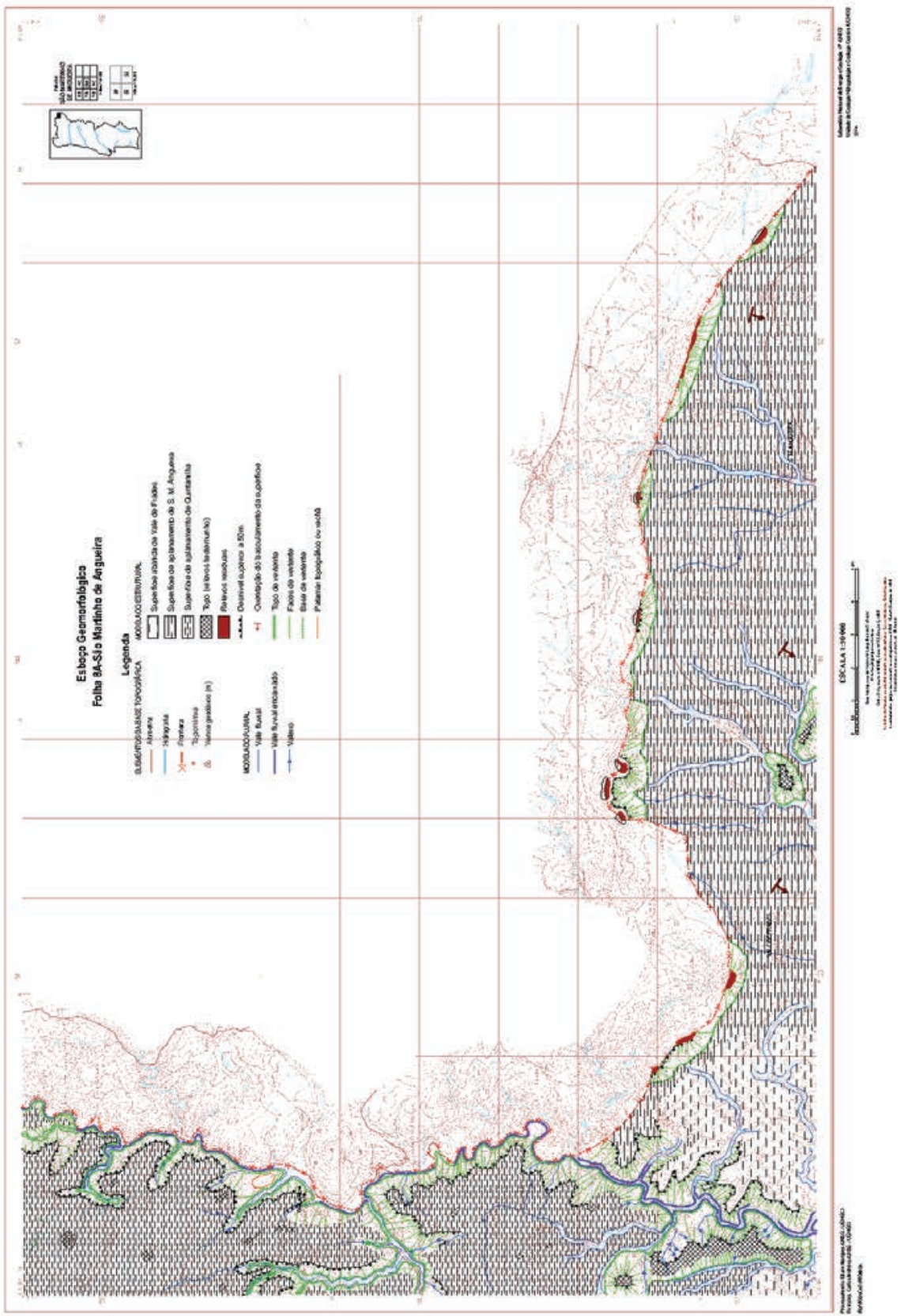

Figura 5 - Esboço geomorfológico para a área correspondente à Folha 8A (em preparação) 
O trabalho agora sucintamente apresentado deverá ser complementado com mais trabalho de campo e de laboratório. A arquitetura dos subtítulos propostos, dependendo muito da área em estudo, poderá, com algumas adaptações da proposta inicial, adequar-se à estrutura e objetivo de uma qualquer Notícia Explicativa. O conhecimento da geomorfologia de uma determinada área e a sua expressão em moldes cartográficos, fornecem uma visão aglutinadora sobre as suas principais características físicas, uma vez que abrange a descrição de aspetos da morfografia, morfometria, morfogénese e morfotectónica. Definir a génese e apontar um plausível quadro de evolução morfológica para uma determinada porção do país, permite uma leitura do território com aplicabilidade no seu planeamento e gestão territorial, com destaque para as questões relacionadas com os riscos naturais e proteção civil.

\section{CONCLUSÃo}

Sendo a cartografia geológica de um país essencial para a divulgação do conhecimento geológico do mesmo (MARQUES, 2012, 82), nada melhor do que complementar a sua elaboração com o contributo interdisciplinar, aproveitando a formação em diferentes áreas dos colaboradores que integram as equipas de trabalho.

A proposta de trabalho descrita, resulta de uma tentativa de sistematização e otimização da estrutura de um dos capítulos da notícia explicativa de uma folha da CGP à escala 1:50 000. A proposta ainda não chegou à fase de publicação, todavia encontra-se neste momento em fase de apreciação conjuntamente com a informação a ser elaborada por autores de outros capítulos. A proposta apresentada, permanece aberta a sugestões positivas, pois resultará sempre de uma construção multidisciplinar com uma finalidade comum. Com esta nova reorganização proposta, cujo resultado em breve será publicado, parece-nos coerente a edição de um novo produto cartográfico - Carta Geomorfológica de Portugal à escala $1: 50000$.

Por fim, é apenas de referir que todo o desenvolvimento de suportes para agregar informação no domínio da cartografia geomorfológica, 
pode proporcionar resultados para encetar trabalhos futuros. Pensamos que com base na proposta que aqui foi sinteticamente descrita, será de encetar esforços futuros na apresentação de um esboço geomorfológico que complemente a folha geológica a publicar, podendo assim dar maior relevo à descrição geomorfológica da área. Todavia, estamos cientes que a representação de formas e processos geomorfológicos apresenta muitas dificuldades quanto à sua conceção, definição de conceitos associados e técnicas de representação simbólica-cartográfica, por si só bastante complexas.

\section{BIBLIOGRAFIA ${ }^{4}$}

ANDRÉ, Maria (2004). SAGISc: Sistema colaborativo para recolha de dados geológicos. Dissertação de Mestrado, Universidade de Lisboa, 137p.

BATEIRA, Carlos (2001). Movimentos de Vertente no NW de Portugal, Susceptibilidade Geomorfológica e Sistemas de informação geográfica. Doutor em Geografia Física, Universidade do Porto, 470p.

COSTA, J. Carríngton \& TEIXEIRA, Carlos (1957). Notícia Explicativa da Folha 9C - Porto. Lisboa, Serviços Geológicos de Portugal, 35p.

CUNHA, Teresa (2008). Cartografia Geológica Digital. A importancia dos SIG na gestão dos recursos geológicos e mitigação dos riscos geológicos naturais e tecnológicos., INETI - Alfragide - Lisboa, INETI, 3-8pp.

FERREIRA, D. Brum (1981). Carte géomorphologique du Portugal. Lisboa, CEG.

FERREIRA, Narciso, et al. (2010). Notícia Explicativa da Folha 17A - Viseu. Lisboa, Laboratório Nacional de Energia e Geologia - Laboratório de Geologia e Minas, 53p.

GANE, Chris. \& SARSON, Trish (1979). Structured systems analysis: tools and techniques, Prentice-Hall, 241p.

ISO5807 (1985). Information processing - Documentation symbols and conventions for data, program and system flowcharts, program network charts and system resources charts. Switzerland - Geneva, International Organization for Standardization. 5807:1985.

MARQUES, Eliane (2012). Cartografia Geológica Digital - Um Percurso Profissional. Mestrado, Universidade do Porto, 228p.

${ }^{4}$ Referências bibliográficas inseridas automaticamente através da aplicação EndNote X6, e apresentadas segunda a norma Autor-Data. 
MARQUES, Eliane \& SOARES, Laura (2010). Inventário e bases de dados de cartografia geomorfológica do NW de Portugal. XII Colóquio Ibérico de Geografia. Porto, Faculdade de Letras da Universidade do Porto, 13p.

MARQUES, Eliane \& Soares, Laura (2011). Inventário e bases de dados de cartografia geomorfológica do NW de Portugal (adaptado do artigo apresentado no XII Colóquio Ibérico de Geografia). CADERNOS - Revista do $3^{\circ}$ Ciclo de Estudos em Geografia. Porto - CEGOT - Faculdade de Letras da Universidade do Porto, vol.3, 31-47 pp.

MEIRELES, Carlos (2012). Folha 8A - São Martinho de Angueira. Carta Geológica de Portugal à escala 1:50 000. LNEG. Lisboa, Laboratório Nacional de Energia e Geologia.

PEÑA-MONNÉ, Jose. (1997). Cartografía Geomorfológica Básica Y Aplicada. Logroño, Geoforma Ediciones, 227p.

REBELO, José (1999). As Cartas geológicas ao serviço do desenvolvimento. Publicação integrada nas Comemorações dos 150 anos da criação da $1^{\circ}$ Comissão Geológica. Lisboa, Instituto Geológico e Mineiro, 55p.

RODRIGUES, José (2010). Folha 7C - Mirandela Carta Geológica de Portugal à escala 1:50 000. LNEG. Lisboa, Laboratório Nacional de Energia e Geologia.

ROMÃO, José et al. (2010). Notícia Explicativa das Folhas 25-C; 25-D; 29-A Rosmaninhal; Segura e Retorta (sector norte). Lisboa, Laboratório Nacional de Energia e Geologia - Laboratório de Geologia e Minas, 53 p. .

SANTOS, José (2005). As bacias de Mirandela, Macedo de Cavaleiros e de VilariçaLongroiva. Estudo de Geomorfologia. Dissertação de Doutoramento, Universidade de Coimbra, 539 p.

SILVA, Thallita \& RODRIGUES, Sílvio (2009). Elaboração de um tutorial de cartografia geomorfológica como alternativa para o ensino de geomorfologia. Rev. Geogr. Acadêmica. Brasil, Instituto de Geografia - Universidade Federal de Uberlândia, vol. 3, 10 p.

SOARES, Laura (2008). A importância das formações superficiais no âmbito dos processos de erosão hídrica e movimentos de vertente no NW de Portugal., Universidade do Porto, 861p.

SOMMERVILLE, Ian (2011). Software engineering. London, Addison-Wesley, 792 p. 
Série Documentos

Imprensa da Universidade de Coimbra

Coimbra University Press

2015

- U M

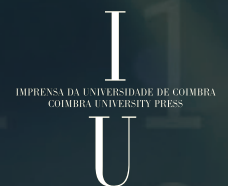

